\title{
Drug resistant tuberculosis in Saudi Arabia: an analysis of surveillance data 2014-2015
}

\author{
Maha Al Ammari ${ }^{1}$, Abdulrahman Al Turaiki', Mohammed Al Essa ${ }^{1,2}$, Abdulhameed M. Kashkary ${ }^{3}$, \\ Sara A. Eltigani ${ }^{3}$ and Anwar E. Ahmed ${ }^{*}$
}

\begin{abstract}
Background: There is limited data that investigates the national rates of drug-resistant tuberculosis (TB) in Saudi Arabia. This study aimed to estimate the rates of multi-drug-resistant tuberculosis (MDR-TB), rifampicin-resistant tuberculosis (RR-TB), and monoresistance (MR) in Saudi Arabia.

Methods: A retrospective cohort study was conducted on all TB cases reported to the National TB Control and Prevention Program (NTCPP) registry at the Saudi Ministry of Health between January 1, 2014 and December 31, 2015. A total of 2098 TB patients with positive TB cultures were included in the study. Subgroup analyses and multivariate binary logistic regression models were performed with IBM SPSS 23.0.

Results: Of the total TB cases, 4.4\% (95\% Cl: 3.59\%-5.40\%) were found to have MDR-TB. The rates of MR were 3.8\% (95\% Cl: 2.99\%-4.67\%) for ethambutol, 5.4\% (95\% Cl: 4.50\%-6.49\%) for pyrazinamide, 10.2\% (95\% Cl: 5. 89\%-11.52\%) for isoniazid, $11 \%$ (95\% Cl: 9.70\%-12.43\%) for streptomycin, and 5.9\% (95\% Cl: 4.90\%-6.96\%) for rifampicin. The high rates of MDR and RR-TB were found among the younger age group, female gender, and those who had a previous history of TB. We also discovered that renal failure tends to increase the risk of rifampicin resistance.

Conclusions: National TB data in Saudi Arabia shows that the rate of MDR-TB was similar to the global rate reported by the World Health Organization (WHO). It is a relatively high rate as compared to Western countries. The proportion of MDR/RR-TB patients tends to be higher in the younger age group, female gender, and in patients with a previous history of TB treatment. Effective strategies for prevention of all multi-drug-resistant TB cases are warranted.
\end{abstract}

Keywords: Mdr-Tb, RR-Tb, Tuberculosis, Anti-TB drugs, Saudi Arabia

\section{Background}

Tuberculosis (TB) is a major public health concern in Saudi Arabia's health system [1]. Despite the implementation of prevention and control measures, TB remains a public health concern in several of the developed world's health systems [2-5]. The World Health Organization (WHO) reported around 10 million newly diagnosed TB cases in 2016 [6].

According to WHO, TB has been ranked Number 11 of the top leading causes of death in Saudi Arabia. A total of 64,345 new TB cases were reported in Saudi Arabia during a period of 20 years (1991 to 2010) [7]. Although TB can be

\footnotetext{
* Correspondence: ahmeda5@vcu.edu

${ }^{4}$ College of Public Health and Health Informatics, King Saud bin Abdulaziz

University for Health Sciences, Riyadh, Saudi Arabia

Full list of author information is available at the end of the article
}

treated in most cases, patient and health-system challenges exist regarding proper utilization of TB treatment, compliance [8], and direct observation of each TB patient under treatment [9]. Unfortunately, TB bacilli may develop resistance to Anti-TB drugs. [10].

MDR-TB (MDR-TB) is defined as resistance to isoniazid and rifampicin, the two most potent anti-TB drugs [11]. Developing resistance to anti-tuberculosis medications has immense implications on the management of TB by 1) increasing the treatment duration, 2) having to use second-line medications with broader side-effects profiles, 3 ) the increased cost of therapy, and 4) the lower success rates $(82 \%$ for drug-susceptible TB, $52 \%$ for MDR-TB, $28 \%$ for XDR-TB) $[6,12,13]$. 
Globally, of all TB patients diagnosed in 2015, 4.6\% of the new TB cases were found to have MDR-TB, in addition to $21 \%$ of the previously treated patients, and it was estimated that there were 480,000 new cases of MDRTB worldwide [6]. The Saudi region-specific rates of MDR-TB were reported between 1 and 5\% [14-16]. A single national study reported an overall MDR-TB rate of $4 \%$ [17]. To date, there has been no other national study that investigates the MDR-TB rate in Saudi Arabia. This epidemiological study aimed to estimate the rates of MDRTB, RR-TB, and monoresistance to anti-TB drugs in Saudi Arabia. We also assessed the association between the demographic and clinical characteristics and the rate of high MDR-TB and RR-TB in the Saudi population.

\section{Methods}

A retrospective cohort study was conducted on all TB cases reported to the National TB Control and Prevention Program (NTCPP) registry at the Saudi Ministry of Health between January 1, 2014 and December 31, 2015. The NTCPP registry is a data registry at the Saudi Ministry of Health, where all suspected and confirmed TB cases are registered from all Saudi Arabian regions, with all related variables that enable researchers and stakeholders to retrieve and analyze any data any period of time. The authors used a retrospective design because it can be useful in identifying the factors associated with the high rates of drug-resistant TB using large-scale existing data. We assessed the drug-resistant TB over a two-year period (January 1, 2014 through December 31, 2015). The Institutional Review Board (IRB) approval was obtained from King Abdullah International Medical Research Center (KAIMRC) in December 2016. All registered TB cases in the NTCPP registry from January 2014 through December 31, 2015 were reviewed. The eligibility criterion was defined as TB cases with positive TB cultures as culture is considered the gold standard method that provides viable organisms to perform DST. DST is the definite diagnostic tool for confirming resistance of Mycobacterium tuberculosis against isoniazid, rifampicin, ethambutol, pyrazinamide, and streptomycin as per program guidelines. No subsample was selected as all TB patients fulfilling the eligibility criteria were included in the study. We extracted demographic data (age, gender, nationality, and place of residence); co-morbidity (renal disease, HIV, diabetes, lung disease, and immunosuppression); type of TB (pulmonary or extra pulmonary); history of previous $\mathrm{TB}$ treatment; and the drug susceptibility test for isoniazid, rifampicin, ethambutol, pyrazinamide, and streptomycin.

\section{Statistical analysis}

We analyzed the data using IBM SPSS Statistics for Windows, version 23 (IBM Corp., Armonk, N.Y., USA). Summary statistics were used to describe the sample characteristics (Table 1). The rates of multi-drugresistant tuberculosis (MDR-TB), rifampicin-resistant tuberculosis (RR-TB), and monoresistance (MR) were described by percentage and $95 \%$ confidence intervals (CI). We estimated the rates of MDR-TB and RR-TB by each of the variables.

\section{Subgroup analyses}

Chi-square/Fisher's Exact were used to test the associations between the sample characteristics across MDR-TB and RIF-resistance (Table 2).

Table 1 Sample characteristics $N=2098$

\begin{tabular}{|c|c|c|c|}
\hline Characteristics & Levels & Mean & SD \\
\hline \multirow[t]{2}{*}{ Age/year } & & 36.6 & 15.9 \\
\hline & & $n$ & $\%$ \\
\hline \multirow[t]{2}{*}{ Gender } & Male & 1449 & 69.1 \\
\hline & Female & 649 & 30.9 \\
\hline \multirow[t]{8}{*}{ Occupation } & Driver & 147 & 7 \\
\hline & Housemaid & 246 & 11.7 \\
\hline & Housewife & 172 & 8.2 \\
\hline & Handcraft & 48 & 2.3 \\
\hline & Student & 148 & 7.1 \\
\hline & Unemployed & 283 & 13.5 \\
\hline & Prisoner & 123 & 5.9 \\
\hline & Other & 931 & 44.4 \\
\hline \multirow[t]{2}{*}{ Nationality } & Saudi & 879 & 41.9 \\
\hline & Non-Saudi & 1219 & 58.1 \\
\hline \multirow[t]{5}{*}{ Region } & Center & 557 & 26.5 \\
\hline & West & 796 & 37.9 \\
\hline & East & 340 & 16.2 \\
\hline & South & 290 & 13.8 \\
\hline & North & 115 & 5.5 \\
\hline \multirow[t]{2}{*}{ TB site } & Pulmonary & 1901 & 90.6 \\
\hline & EPTB & 197 & 9.4 \\
\hline \multirow[t]{2}{*}{ Diabetes } & Yes & 267 & 12.7 \\
\hline & No & 1831 & 87.3 \\
\hline \multirow[t]{2}{*}{ HIV } & Yes & 45 & 2.1 \\
\hline & No & 2053 & 97.9 \\
\hline \multirow[t]{2}{*}{ Lung diseases } & Yes & 54 & 2.6 \\
\hline & No & 2044 & 97.4 \\
\hline \multirow[t]{2}{*}{ Chronic renal failure } & Yes & 19 & 0.9 \\
\hline & No & 2079 & 99.1 \\
\hline \multirow[t]{2}{*}{ Immunosuppressive } & Yes & 13 & 0.6 \\
\hline & No & 2085 & 99.4 \\
\hline \multirow[t]{2}{*}{ Previous TB treatment } & Yes & 143 & 6.8 \\
\hline & No & 1955 & 93.2 \\
\hline
\end{tabular}

SD Standard deviation, HIV human immunodeficiency virus, $T B$ tuberculosis 


\section{Multivariate analyses}

We used multivariate logistic models to identify the factors related to MDR-TB and RIF-resistance (Table 3). All variables assessed by the subgroup analyses were included in the multivariate models. The strength of the relation was assessed using unadjusted and adjusted odds ratios OR and
aOR)and 95\% CI (Table 2 and Table 3, respectively). In all analyses, the significance level was determined at $P \leq 0.05$.

\section{Results}

A total of 6753 patients included in NTCPP registry from January 1, 2014 through December 31, 2015 were

Table 2 Bivariate factors associated with MDR-TB and RR-TB

\begin{tabular}{|c|c|c|c|c|c|c|c|c|c|c|c|c|c|}
\hline \multirow[b]{3}{*}{ Characteristics } & \multirow[b]{3}{*}{ Levels } & \multicolumn{2}{|l|}{$\begin{array}{l}\text { MDR-TB } \\
93(4.4 \%) \\
\end{array}$} & \multirow[b]{3}{*}{$P$} & \multirow[b]{3}{*}{ OR } & & & \multicolumn{2}{|l|}{$\begin{array}{l}\text { RR-TB } \\
123(5.9 \%) \\
\end{array}$} & \multirow[b]{3}{*}{$P$} & \multirow[b]{3}{*}{ OR } & \multirow{2}{*}{\multicolumn{2}{|c|}{$95 \% \mathrm{Cl}$ for $\mathrm{OR}$}} \\
\hline & & & & & & \multicolumn{2}{|c|}{$95 \% \mathrm{Cl}$ for $\mathrm{OR}$} & & & & & & \\
\hline & & $\begin{array}{l}\text { Mean } \\
\text { Difference }\end{array}$ & $\begin{array}{l}\text { SE } \\
\text { Difference }\end{array}$ & & & Lower & Upper & $\begin{array}{l}\text { Mean } \\
\text { Difference }\end{array}$ & $\begin{array}{l}\text { SE } \\
\text { Difference }\end{array}$ & & & Lower & Upper \\
\hline \multirow[t]{3}{*}{ Age/year } & & 3.8 & 1.4 & $0.006^{a}$ & .983 & .968 & .998 & 2.547 & 1.5 & .084 & .989 & .977 & 1.001 \\
\hline & & & & & & \multicolumn{4}{|c|}{$95 \% \mathrm{Cl}$ for OR } & & & \multicolumn{2}{|c|}{$95 \% \mathrm{Cl}$ for OR } \\
\hline & & $\mathrm{n}$ & $\%$ & $P$ & OR & Lower & Upper & $n$ & $\%$ & $\mathrm{P}$ & OR & Lower & Upper \\
\hline \multirow[t]{2}{*}{ Gender } & Male & 60 & 4.1 & 0.332 & 1.240 & .803 & 1.916 & 84 & 5.8 & 0.848 & 1.039 & .702 & 1.537 \\
\hline & Female & 33 & 5.1 & & & & & 39 & 6 & & 1 & & \\
\hline \multirow[t]{8}{*}{ Occupation } & Driver & 8 & 5.4 & 0.984 & 1.133 & .523 & 2.455 & 10 & 6.8 & 0.918 & 1.060 & .530 & 2.119 \\
\hline & Housemaid & 10 & 4.1 & & .834 & .414 & 1.680 & 12 & 4.9 & & .744 & .394 & 1.407 \\
\hline & Housewife & 6 & 3.5 & & .712 & .299 & 1.695 & 7 & 4.1 & & .616 & .277 & 1.371 \\
\hline & Handcraft & 2 & 4.2 & & .856 & .201 & 3.639 & 3 & 6.3 & & .968 & .292 & 3.205 \\
\hline & Student & 6 & 4.1 & & .832 & .349 & 1.986 & 7 & 4.7 & & .721 & .323 & 1.608 \\
\hline & Unemployed & 11 & 3.9 & & .796 & .406 & 1.561 & 17 & 6 & & .928 & .532 & 1.617 \\
\hline & Prisoner & 5 & 4.1 & & .834 & .325 & 2.144 & 7 & 5.7 & & .876 & .391 & 1.962 \\
\hline & Other & 45 & 4.8 & & 1 & & & 60 & 6.4 & & 1 & & \\
\hline \multirow[t]{2}{*}{ Nationality } & Saudi & 34 & 3.9 & 0.286 & 1.264 & .821 & 1.946 & 51 & 5.8 & 0.920 & 1.019 & .704 & 1.475 \\
\hline & Non-Saudi & 59 & 4.8 & & 1 & & & 72 & 5.9 & & 1 & & \\
\hline \multirow[t]{5}{*}{ Region } & West & 43 & 5.4 & $0.014^{a}$ & .937 & .585 & 1.500 & 54 & 6.8 & $0.004^{a}$ & .892 & .587 & 1.356 \\
\hline & East & 5 & 1.5 & & .245 & .094 & .635 & 6 & 1.8 & & .220 & .093 & .524 \\
\hline & South & 9 & 3.1 & & .525 & .247 & 1.116 & 17 & 5.9 & & .764 & .427 & 1.367 \\
\hline & North & 4 & 3.5 & & .591 & .205 & 1.705 & 4 & 3.5 & & .442 & .155 & 1.258 \\
\hline & Center & 32 & 5.7 & & 1 & & & 42 & 7.5 & & 1 & & \\
\hline \multirow[t]{2}{*}{ TB site } & Pulmonary & 87 & 4.6 & 0.320 & 1.527 & .659 & 3.539 & 113 & 5.9 & 0.622 & 1.182 & .608 & 2.296 \\
\hline & EPTB & 6 & 3 & & 1 & & & 10 & 5.1 & & 1 & & \\
\hline \multirow[t]{2}{*}{ Diabetes } & Yes & 9 & 3.4 & 0.367 & 1.378 & .685 & 2.775 & 14 & 5.2 & 0.645 & 1.144 & .646 & 2.027 \\
\hline & No & 84 & 4.6 & & 1 & & & 109 & 6 & & 1 & & \\
\hline \multirow[t]{2}{*}{ HIV } & Yes & 92 & 4.5 & 1.000 & 2.064 & .281 & 15.148 & 121 & 5.9 & 0.720 & 1.347 & .322 & 5.625 \\
\hline & No & 1 & 2.2 & & 1 & & & 2 & 4.4 & & 1 & & \\
\hline \multirow[t]{2}{*}{ Lung diseases } & Yes & 2 & 3.7 & 1.000 & .825 & .198 & 3.442 & 4 & 7.4 & 0.555 & 1.294 & .460 & 3.644 \\
\hline & No & 91 & 4.5 & & 1 & & & 119 & 5.8 & & 1 & & \\
\hline \multirow{2}{*}{$\begin{array}{l}\text { Chronic renal } \\
\text { failure }\end{array}$} & Yes & 2 & 10.5 & 0.205 & 2.570 & .585 & 11.292 & 4 & 21.1 & $0.022^{\mathrm{a}}$ & 4.392 & 1.435 & 13.439 \\
\hline & No & 91 & 4.4 & & 1 & & & 119 & 5.7 & & 1 & & \\
\hline \multirow[t]{2}{*}{ Immunosuppressive } & Yes & 1 & 7.7 & 0.446 & 1.805 & .232 & 14.032 & 2 & 15.4 & 0.175 & 2.951 & .647 & 13.463 \\
\hline & No & 92 & 4.4 & & 1 & & & 121 & 5.8 & & 1 & & \\
\hline \multirow{2}{*}{$\begin{array}{l}\text { Previous TB } \\
\text { treatment }\end{array}$} & Yes & 36 & 25.2 & $0.001^{a}$ & 11.203 & 7.069 & 17.755 & 41 & 28.7 & $0.001^{a}$ & 9.181 & 6.005 & 14.038 \\
\hline & No & 57 & 2.9 & & 1 & & & 82 & 4.2 & & 1 & & \\
\hline
\end{tabular}


Table 3 Multivariate factors associated with MDR-TB and RR-TB

\begin{tabular}{|c|c|c|c|c|c|c|c|c|c|}
\hline \multirow[b]{3}{*}{ Factor } & & \multicolumn{4}{|c|}{ MDR-TB } & \multicolumn{4}{|l|}{ RR-TB } \\
\hline & & \multirow[b]{2}{*}{$P$} & \multirow[b]{2}{*}{$\mathrm{aOR}$} & \multicolumn{2}{|c|}{$95 \% \mathrm{Cl}$ for $\mathrm{aOR}$} & \multirow[b]{2}{*}{$P$} & \multirow[b]{2}{*}{$\mathrm{aOR}$} & \multicolumn{2}{|c|}{$95 \% \mathrm{Cl}$ for $\mathrm{aOR}$} \\
\hline & & & & Lower & Upper & & & Lower & Upper \\
\hline Age & & $0.032^{\mathrm{a}}$ & 0.98 & 0.962 & 0.998 & $0.047^{\mathrm{a}}$ & 0.98 & 0.970 & 1.000 \\
\hline Female & Male & $0.015^{\mathrm{a}}$ & 2.21 & 1.170 & 4.181 & $0.044^{\mathrm{a}}$ & 1.78 & 1.015 & 3.120 \\
\hline Occupation: Driver & Other & 0.232 & 1.68 & 0.718 & 3.932 & 0.285 & 1.51 & 0.708 & 3.237 \\
\hline Occupation: Housemaid & Other & 0.116 & 0.49 & 0.200 & 1.193 & 0.147 & 0.55 & 0.246 & 1.234 \\
\hline Occupation: Housewife & Other & $0.036^{\mathrm{a}}$ & 0.33 & 0.114 & 0.932 & $0.010^{\mathrm{a}}$ & 0.28 & 0.109 & 0.744 \\
\hline Occupation: Hand Craft & Other & 0.390 & 1.93 & 0.430 & 8.654 & 0.241 & 2.11 & 0.606 & 7.342 \\
\hline Occupation: Student & Other & 0.113 & 0.44 & 0.157 & 1.217 & $0.037^{\mathrm{a}}$ & 0.37 & 0.144 & 0.940 \\
\hline Occupation:Unemployed & Other & 0.395 & 0.72 & 0.338 & 1.534 & 0.267 & 0.70 & 0.370 & 1.317 \\
\hline Occupation: Prisoner & Other & 0.771 & 0.86 & 0.313 & 2.369 & 0.584 & 0.79 & 0.330 & 1.868 \\
\hline Saudi & Non-Saudi & 0.921 & 0.97 & 0.569 & 1.664 & 0.583 & 1.14 & 0.716 & 1.813 \\
\hline West & Center & 0.624 & 0.88 & 0.522 & 1.477 & 0.371 & 0.81 & 0.514 & 1.282 \\
\hline East & Center & $0.038^{a}$ & 0.35 & 0.131 & 0.942 & $0.005^{\mathrm{a}}$ & 0.28 & 0.115 & 0.685 \\
\hline South & Center & 0.181 & 0.57 & 0.254 & 1.296 & 0.552 & 0.82 & 0.437 & 1.556 \\
\hline North & Center & 0.710 & 0.81 & 0.274 & 2.418 & 0.273 & 0.55 & 0.189 & 1.601 \\
\hline TB Type: Pulmonary & EPTB & 0.480 & 1.38 & 0.565 & 3.375 & 0.766 & 1.11 & 0.548 & 2.260 \\
\hline Diabetes & No & 0.835 & 0.92 & 0.411 & 2.052 & 0.874 & 0.95 & 0.486 & 1.847 \\
\hline HIV & No & 0.469 & 2.34 & 0.234 & 23.392 & 0.416 & 2.14 & 0.343 & 13.353 \\
\hline Lung diseases & No & 0.549 & 0.63 & 0.138 & 2.868 & 0.789 & 0.85 & 0.271 & 2.693 \\
\hline Chronic renal failure & No & 0.102 & 4.01 & 0.759 & 21.231 & $0.004^{a}$ & 6.61 & 1.860 & 23.495 \\
\hline Immunosuppressive & No & 0.738 & 1.56 & 0.116 & 21.008 & 0.262 & 3.18 & 0.420 & 24.113 \\
\hline Previous TB treatment & No & $0.001^{\mathrm{a}}$ & 12.08 & 7.325 & 19.927 & $0.001^{\mathrm{a}}$ & 9.33 & 5.920 & 14.717 \\
\hline (Intercept) & & 0.003 & 0.02 & & & 0.002 & 0.04 & & \\
\hline
\end{tabular}

${ }^{a}$ Significant at $\mathrm{a}=0.05 ; a O R$ adjusted odds ratio, TB Tuberculosis, HIV human immunodeficiency virus, MDR-TB multi-drug-resistant tuberculosis, RR-TB rifampicinresistant tuberculosis, EPTB extra-pulmonary tuberculosis. The percentages of correct classification were $95.6 \%$ for MDR-TB and $94.1 \%$ for RR-TB

reviewed. Around 4655 patients were excluded due to non-availability of culture results, or non-availability of rifampicin-susceptibility test results. A total of 2098 patients with positive TB cultures enrolled in the study for the final analysis.

The mean age was $36.6(\mathrm{SD}=15.9)$ years. Of the TB cases, $69.1 \%$ were male, $11.7 \%$ were housemaids, and $41.9 \%$ were Saudi. About 38\% of these TB cases occurred in the Western region of Saudi Arabia. Pulmonary tuberculosis was common in TB patients (90.6\%), while $9.4 \%$ had extra-pulmonary tuberculosis (EPTB). More details can be found in Table 1. The rate for MDR-TB in TB patients studied was 4.4\% (95\% CI: $3.59 \%-5.40 \%$ ), while the resistance rate was $3.8 \%$ (95\% CI: $2.99 \%-4.67 \%$ ) for ethambutol, $5.4 \%$ (95\% CI: $4.50 \%-6.49 \%$ ) for pyrazinamide, $5.9 \%$ (95\% CI: 4.90\%-6.96\%) for rifampicin, 10.2\% (95\% CI: $5.89 \%-11.52 \%$ ) for isoniazid, and 11\% (95\% CI: $9.70 \%-12.43 \%)$ for streptomycin.

According to subgroup analyses (Table 2), the resistance rates for MDR/RR-TB were low in the Eastern region. The resistance rates for MDR-TB and RR-TB were high in patients with previous anti-TB treatment, and chronic renal failure was associated with a higher rate of RR-TB. There was no association regarding gender, age, TB site, nationality, or HIV status. According to multivariate logistic models (Table 3), the female gender is more likely to have MDRTB and RR-TB (2.21 and 1.78 times) as compared to the male gender, respectively. As age increases by 1 year, MDRTB and RIF-resistance tend to decrease by $2 \%$.

In comparison to patients with no previous anti-TB treatment, MDR-TB and RR-TB were 12.08 and 9.33, respectively, times more likely to occur in patients with previous TB treatment. Patients from the Eastern region are less likely to develop MDR-TB and RR-TB by $65 \%$ and $72 \%$ respectively, compared with patients from the Central region. Compared to patients with no renal failure, patients with renal failure were 6.61 times more likely to have RR-TB. Housewives, compared to other occupations, were $67 \%$ and $72 \%$ less likely to have MDR-TB and RR-TB, respectively.

\section{Discussion}

Our data showed that the rate of MDR-TB in Saudi Arabia is within the global average as per the 2016 WHO 
report [6]. Similar to a previous Al-Hajoj et al. study, our study revealed that the Western and Central regions showed the highest rates of MDR-TB and Eastern region was the lowest [17]. The high rates in the Western region could be due to the presence of the two biggest holy sites (Mecca and Medina), which are visited by millions of Muslim from all around the world, including from countries where TB is highly endemic. During Hajj season, TB is the most frequent cause of hospitalization [18]. In the Central region we expected the higher rate could be due to the presence of four tertiary care hospitals in addition to the $\mathrm{MOH}$ central hospital and the chest hospital, that serve as referral centers from the periphery for all suspected and confirmed TB cases.

Comparing our result with the Al-Hajhoj study, there were slightly higher rates of MDR-TB (4.4\% vs. $4.0 \%)$ and RR-TB in our study ( $5.8 \%$ vs. $5.3 \%$ ), respectively. Comparing the rate of MDR-TB in the newly treated patients, the Al-Hajhoj study showed $1.8 \%$ of newly treated patients had MDR-TB, while our study showed a higher rate of MDR-TB (2.9\%) among the newly diagnosed patients [17]. Our study showed consistent results with several published studies regarding previously treated patients and the risk of MDR-TB [17, 19-24].

Our study also revealed that each one-year increase was associated with a $2 \%$ decrease in MDR-TB. This was similar to what was seen in a European meta-analysis, which showed that patients younger than 65 years of age were associated with a higher risk of MDR-TB [19] and in an Ethiopian study, which showed that patients younger than 25 years of age had an increased risk of MDR-TB [20]. This association could be explained by the fact that younger patients have lower compliance to the medication compared with the elderly.

In our study, the female gender was associated with a higher rate of MDR-TB compared with males. This finding contradicted the results of the previously mentioned metaanalysis, which showed that males have a higher chance of developing MDR-TB when compared to females [19].

This study has several limitations: the data were collected retrospectively, and due to the nature of the study, we did not include modifiable factors such as patient compliance and appropriateness of regimen. These factors could be important in developing anti-TB resistance as is shown in a study conducted in Turkey in 2004 [24]. Data were not available for close contact with other MDR-TB patients, alcohol use, and monthly income in our patients, which may be important factors for a high rate of MDR-TB as was shown in the Mulu study [20]. No data on intravenous drug abuse was collected, however it was found to be associated with MDR-TB in a 2014 study conducted in Portugal [23]. Despite these limitations, the study determined the overall MDR-TB rate and TB patients with high risk in Saudi Arabia. The study may be helpful to policymakers wanting to address the rising concern of MDR-TB in Saudi Arabia.

\section{Conclusion}

National TB data in Saudi Arabia shows the rate of MDR-TB is in accordance with global rates, however, it is a relatively high rate when compared to Western countries. The proportion of MDR/RR-TB cases tends to increase in younger age group, female gender, and in patients with previous TB treatment. The rates of MDR/ RR-TB varied between regions in Saudi Arabia, with the Eastern region reporting the lowest MDR-TB rate. Further studies are required to understand the association between the suggested high risk and drug-resistant TB. It will help in addressing the early identification of the drug-resistant TB patients and their management.

\section{Acknowledgements}

We would like to thank the National Tuberculosis Control and Prevention Program personnel for providing the data used in this research and for their support. The authors would like to thank King Abdullah International Medical Research Center for approving and funding this study.

\section{Funding}

Funding for publication fees for open access was obtained from King Abdullah International Medical Research Center.

\section{Availability of data and materials}

Please contact authors for data request.

\section{Authors' contributions}

MA, AA, and MAA conceived and designed the study and drafted the manuscript. AEA carried out the data analysis, prepared the results and the abstract sections, and revised the manuscript. AMK and SAE revised the draft of the manuscript. All authors read and approved the final manuscript.

Ethics approval and consent to participate

The study received ethical approval from the Institutional Review Board (IRB) at Saudi Ministry of Health and King Abdullah International Medical Research Center.

Consent for publication

Not applicable.

\section{Competing interests}

The authors declare that they have no competing interests. Open Choice: Yes.

\section{Publisher's Note}

Springer Nature remains neutral with regard to jurisdictional claims in published maps and institutional affiliations.

\section{Author details}

${ }^{1}$ King Abdullah International Medical Research Center (KAIMRC)/King Abdulaziz Medical City(KAMC), Ministry of National Guard - Health Affairs, Riyadh, Saudi Arabia. ${ }^{2}$ College of Pharmacy, King Saud bin Abdulaziz University for Health Sciences, Riyadh, Saudi Arabia. ${ }^{3}$ Ministry of Health Kingdom of Saudi Arabia, Riyadh, Saudi Arabia. ${ }^{4}$ College of Public Health and Health Informatics, King Saud bin Abdulaziz University for Health Sciences, Riyadh, Saudi Arabia. 
Received: 16 March 2017 Accepted: 15 January 2018

Published online: 22 January 2018

\section{References}

1. Abouzeid MS, Zumla Al, Felemban S, Alotaibi B, O'Grady J, Memish ZA. Tuberculosis trends in Saudis and non-Saudis in the Kingdom of Saudi Arabiaa 10 year retrospective study (2000-2009). PLoS One. 2012;7(6):e39478.

2. Main $C L$, Ying $E$, Wang EE. How much does it cost to manage paediatric tuberculosis? One-year experience from the Hospital for Sick Children. Can J Infect Dis Med Microbiol. 1998;9(6):354-8.

3. McGowan JE, Blumberg HM. Inner-city tuberculosis in the USA. J Hosp Infect. 1995;30:282-95.

4. Fiebig L, Kollan C, Hauer B, Gunsenheimer-Bartmeyer B, an der Heiden M, Hamouda O, Haas W. HIV-prevalence in tuberculosis patients in Germany, 2002-2009: an estimation based on HIV and tuberculosis surveillance data. PLoS One. 7(11):e49111.

5. Allen AR, Minozzi G, Glass EJ, et al. Bovine tuberculosis: the genetic basis of host susceptibility. Proceedings of the Royal Society B: Biological Sciences. 2010;277(1695):2737-45. https://doi.org/10.1098/rspb.2010.0830.

6. World Health Organization. Global tuberculosis report 2016

7. Al-Orainey I, Alhedaithy MA, Alanazi AR, Barry MA, Almajid FM. Tuberculosis incidence trends in Saudi Arabia over 20 years: 1991-2010. Annals Thoracic Med. 2013;8(3):148.

8. Cambau E, Viveiros M, Machado D, Raskine L, Ritter C, Tortoli E, Matthys V, Hoffner S, Richter E, Del Molino MP, Cirillo DM. Revisiting susceptibility testing in MDR-TB by a standardized quantitative phenotypic assessment in a European multicentre study. J Antimicrob Chemother. 2015;70(3):686-96.

9. Jain A, Dixit P. Multidrug resistant to extensively drug resistant tuberculosis: what is next? J Biosci. 2008;33(4):605.

10. Villarino ME, Geiter $\sqcup$, Simone PM. The multidrug-resistant tuberculosis challenge to public health efforts to control tuberculosis. Public Health Rep. 1992;107(6):616.

11. Laserson KF, Thorpe LE, Leimane V, Weyer K, Mitnick CD, Riekstina V, Zarovska E, Rich ML, Fraser HS, Alarcón E, Cegielski JP. Speaking the same language: treatment outcome definitions for multidrug-resistant tuberculosis. Int J Tuberc Lung Dis. 2005;9(6):640-5.

12. World Health Organization (WHO). Treatment of tuberculosis: guidelines for national programmes. Geneva: WHO; 2003. WHO/CDS/TB/2003.313.

13. Cegielski JP. Extensively drug-resistant tuberculosis:"there must be some kind of way out of here". Clin Infect Dis. 2010;50(Supplement 3):S195-200.

14. Chaudhry LA, Rambhala N, Al-Shammri AS, Al-Tawfiq JA. Patterns of antituberculous drug resistance in eastern Saudi Arabia: a 7-year surveillance study from 1/2003 to 6/2010. J Epidemiol Global Health. 2012;2(1):57-60.

15. Asaad AM, Alqahtani JM. Primary anti-tuberculous drugs resistance of pulmonary tuberculosis in southwestern Saudi Arabia. J Infect Public Health. 2012;5(4):281-5.

16. Elhassan M, Hemeg HA, Elmekki MA, Turkistani KA, Abdul-Aziz AA. Burden of Multidrug Resistant Mycobacterium tuberculosis Among New Cases in AlMadinah Al-Monawarah, Saudi Arabia. Infect Disord Drug Targets (Formerly Current Drug Targets-Infectious Disorders). 2017:17(1):14-23.

17. Al-Hajoj S, Varghese B, Shoukri MM, Al-Omari R, Al-Herbwai M, AlRabiah F, Alrajhi AA, Abuljadayel N, Al-Thawadi S, Zumla A, Zignol M. Epidemiology of antituberculosis drug resistance in Saudi Arabia: findings of the first national survey. Antimicrob Agents Chemother. 2013;57(5):2161-6.

18. Alzeer A, Mashlah A, Fakim N, Al-Sugair N, Al-Hedaithy M, Al-Majed S, Jamjoom G. Tuberculosis is the commonest cause of pneumonia requiring hospitalization during hajj (pilgrimage to Makkah). J Infect. 1998;36(3):303-6.

19. Faustini A, Hall AJ, Perucci CA. Risk factors for multidrug resistant tuberculosis in Europe: a systematic review. Thorax. 2006;61(2):158-63.

20. Mulu W, Mekkonnen D, Yimer M, Admassu A, Abera B. Risk factors for multidrug resistant tuberculosis patients in Amhara National Regional State. Afr Health Sci. 2015;15(2):368-77.

21. Barroso EC, Mota RM, Santos RO, Sousa AL, Barroso JB, Rodrigues JL. Risk factors for acquired multidrug-resistant tuberculosis. J Pneumol 2003;29(2):89-97.

22. Gomes M, Correia A, Mendonça D, Duarte R. Risk factors for drug-resistant tuberculosis. J Tuberc Res. 2014:3:2014.

23. Ruddy M, Balabanova Y, Graham C, Fedorin I, Malomanova N, Elisarova E, Kuznetznov S, Gusarova G, Zakharova S, Melentyev A, Krukova E. Rates of drug resistance and risk factor analysis in civilian and prison patients with tuberculosis in Samara region, Russia. Thorax. 2005;60(2):130-5.

24. Karabay O, Otkum M, Akata F, Karlikaya C, Tugrul M, Dundar V. Antituberculosis drug resistance and associated risk factors in the European section of Turkey. Indian J Chest Dis Allied Sci. 2004;46:171-8.

\section{Submit your next manuscript to BioMed Central and we will help you at every step:}

- We accept pre-submission inquiries

- Our selector tool helps you to find the most relevant journal

- We provide round the clock customer support

- Convenient online submission

- Thorough peer review

- Inclusion in PubMed and all major indexing services

- Maximum visibility for your research

Submit your manuscript at www.biomedcentral.com/submit 